San Jose State University

SJSU ScholarWorks

Faculty Publications, Chemistry

Chemistry

$1-1-2000$

\title{
Spin-Exchange Term in the Solvent Equation of State Near the Critical Point for Electron Transfer Reactions
}

Juana Vivó Acrivos

San Jose State University, juana.acrivos@sjsu.edu

Follow this and additional works at: https://scholarworks.sjsu.edu/chem_pub

Part of the Physical Chemistry Commons

\section{Recommended Citation}

Juana Vivó Acrivos. "Spin-Exchange Term in the Solvent Equation of State Near the Critical Point for Electron Transfer Reactions" Journal Solid of State Chemistry (2000): 10l-110. https://doi.org/10.1006/ jssc. 1999.8629

This Article is brought to you for free and open access by the Chemistry at SJSU ScholarWorks. It has been accepted for inclusion in Faculty Publications, Chemistry by an authorized administrator of SJSU ScholarWorks. For more information, please contact scholarworks@sjsu.edu. 


\title{
Spin Exchange Term in the Solvent Equation of State Near the Critical Point for Electron Transfer Reactions
}

\author{
J.V. Acrivos*, San José State University, San José CA95192-0101
}

To the Memory of Kenneth Sanborn Pitzer

Keywords:

electron spin exchange reactions, equations of state for supercritical metallic, semi-metallic, polar and non polar solvents

*Corresponding author:

telephone: 4089244972

tele-fax: 4089244945

email: jacrivos@athens.sjsu.edu

www.sjsu.edu /faculty/Acrivos/front.html 


\begin{abstract}
:
Phenomenological Equations of State (EOS) for fluids near their critical point have been obtained using literature compression factor data, $Z_{c}=P_{c} V_{c} /\left(n R T_{c}\right)=0.40$ to 0.10 in Table I $\left(\mathrm{P}_{\mathrm{c}}, \mathrm{V}_{\mathrm{c}} / \mathrm{n}, \mathrm{T}_{\mathrm{c}}\right.$ are the pressure, volume per $\mathrm{n}$ mole, and the absolute temperature of the fluid at the critical point). The objective is to explain the deviations from the van der Waals value, $Z_{c}(v d W)=3 / 8(-70 \%$ for molten Se and alkali metals up to $6 \%$ for molten $\mathrm{Pb}, \mathrm{Hg}$, and In) by including in the commonly used phenomenological thermodynamic relations a term which explicitly describes the Heisenberg spin exchange interactions, in order to understand electron transfer reactions in solvents near their critical point. Literature data near the critical point indicate that the ${ }^{199,201} \mathrm{Hg}\left(Z_{c} \cong 0.4\right)$ Knight shift plummets to zero while the alkali metals and Se $\left(Z_{c}=0.2\right.$ to 0.1$)$ are paramagnetic fluids, and that the enhanced rates for free radical electron exchange reactions (in $\mathrm{CO}_{2}, n-\mathrm{C}_{2} \mathrm{H}_{6}$ and $\mathrm{CHF}_{3}$ with intermediate $\mathrm{Z}_{\mathrm{c}}$ ) are correlated to $Z_{c}$. The difference between the solvent behavior for electron spin exchange reactions near its critical point is ascribed to spin interactions. The analysis shows that the solvated electron osmotic pressure in metal ammonia solutions versus the solvent density $\rho_{\mathrm{r}, \mathrm{NH} 3}=\mathrm{V}_{\mathrm{C}} / \mathrm{V}$ goes through a maximum where enhanced rates of electron exchange also attain a maximum. This can be applied to choose the best solvents, near their critical point, for the syntheses of new materials and metal oxide extraction.
\end{abstract}




\section{Introduction:}

Supercritical fluids are used in chemical synthesis due to the increased solubility and chemical reactivity of materials in fluids near and above their critical point ${ }^{1}$. Under supercritical solvent conditions, electron exchange reactions must take into account the spinspin exchange interactions ${ }^{2,3}$.

This work is an attempt to use simple and available compression factor data (near the critical point of fluids) to ascertain the contribution to electron exchange reactions of the spinspin interaction terms going from molten metals, to polar, to non-polar fluids. The deviations from the van der Waals value, $Z_{c}(v d W)=3 / 8$ in Table I ${ }^{4}$ are the basis for the hypothesis. The gradual change in $Z_{c}$ between the two extremes $\mathrm{Hg}\left(Z_{c} \cong 0.4\right)$ to alkali metals and $\mathrm{Se}\left(Z_{c} \cong 0.2\right.$ to 0.1 ) is explained in this work, by a semiempirical approach, which adds to the EOS an interaction term that describes the spin exchange interaction explicitly ${ }^{5 a}$. The ${ }^{199,201} \mathrm{Hg}$ Knight shift plummets to zero, and Se dissociates into metallic chains at the critical point ${ }^{4 \mathrm{~d}}$. Electron spin resonance (esr) measurements at ordinary pressures measure the Heisenberg spin exchange interactions. In the intermediate region, $0.3 \geq Z_{c} \geq 0.2$, the solvent temperature and pressure dependent spin exchange rate constants ${ }^{4 h, 0}$ and magnitudes of the free radical isotropic nuclear hyperfine coupling constants ${ }^{6-8}$ indicate that the solvent is not a passive medium: In alkali metal in ammonia/amine solutions ${ }^{6}$, in most free radical solutions ${ }^{7}$, and in solids $^{8}$ the free electron spin density extends into the surrounding medium. The transferred electron density, $\mathrm{n}_{\mathrm{e}} / \mathrm{V}$ is proportional to the solvent particle density, $\mathrm{n} / \mathrm{V}$ surrounding the solute, and the spin exchange energy density varies $a^{5 a, b}\left(n_{e} / V\right)^{4 / 3}$, thus the term which describes the Heisenberg spin interaction varies as $(n / V)^{4 / 3}$ in the EOS of fluids near the critical point. More accurate EOS (obtained by careful T, V, P measurements) are necessary 
to describe the system by scaling concepts ${ }^{9-11}$. However, the important question to be answered is what determines the boundaries between metallic, semi-metallic, polar and nonpolar solvents for electron transfer reactions in the solvent critical region?

\section{Spin Exchange for Free Radicals in Solution and in Liquid Metals}

The extreme variations in $Z_{c}$ ( 0.4 for diamagnetic Hg clusters to 0.1 for paramagnetic Se chains $^{4, \mathrm{~d}}$ ) can not be explained by a simple Lennard-Jones hard spheres approximation. The experimental evidence for intermediate $Z_{c}$, (by different type of measurements near the solvent critical point ${ }^{4 f, h, j, 0}$ ) is that there is an enhancement in the electron exchange rates over that calculated by Brownian dynamics simulations, and that this is solvent dependent:

- ESR measurements on di-tert-butyl nitroxide (DTBN) free radical, dissolved in ethane near its critical point $\left(Z_{c}=0.279^{4 i}\right.$ at $T_{r}=T / T_{C}=1.01$, and different $P_{r}=P / P_{c}$ reproduced in Figure 1a from ref. 4f) give rates for the spin exchange reaction:

$$
\mathrm{DTBN}_{\mathrm{Sz}=1 / 2}+\mathrm{DTBN}_{\mathrm{Sz}=-1 / 2}=\mathrm{DTBN}_{\mathrm{Sz}=-1 / 2}+\mathrm{DTBN}_{\mathrm{Sz}=1 / 2}
$$

which are faster than can be explained by chemical dynamics' simulations near the critical point $^{4 f, \mathrm{~h}, \mathrm{j}, \mathrm{k}}$. The authors obtained extreme variations in the second order rate constants, $\mathrm{k}_{\mathrm{ex}}$ $=0.2 \mathrm{l} / \mathrm{mol} / \mathrm{ps}$ at $\mathrm{T}_{\mathrm{r}}=1.01$ to $0.05 \mathrm{l} / \mathrm{mol} / \mathrm{ps}$ at $\mathrm{T}_{\mathrm{r}}=1.08$, and a volume increase to the activated transition state complex for spin exchange, $\Delta \mathrm{V}^{\neq}=\left(\partial \Delta \mathrm{G}^{\neq} / \partial \mathrm{P}\right)_{\mathrm{T}}=-\mathrm{RT}\left(\partial \operatorname{lnk}_{\mathrm{ex}} / \partial \mathrm{P}\right)_{\mathrm{T}}$ which is much greater than normal fluid activation volumes of $0.05 \mathrm{l} / \mathrm{mol} . \Delta \mathrm{V}^{\ddagger}=7.5 \mathrm{l}$ $/ \mathrm{mol}$ at $\mathrm{T}_{\mathrm{r}}=1.01, \mathrm{P}_{\mathrm{r}} \cong 1.04$ (or $6.3 \mathrm{~nm}^{3} / \mathrm{DTBN}$ spin exchanged) to $1 \mathrm{l} / \mathrm{mol}$ at $\mathrm{T}_{\mathrm{r}}=1.08, \mathrm{P}_{\mathrm{r}}$ $\cong 1.4$ (or $0.85 \mathrm{~nm}^{3} / \mathrm{DTBN}$ spin exchanged) ${ }^{4 f}$. The magnitude of the ${ }^{14} \mathrm{~N}$ hyperfine tensor for DTBN goes from $17.2 \mathrm{G}$ in aqueous solutions ${ }^{7 b}$ to below $15 \mathrm{G}$ in $\mathrm{C}_{2} \mathrm{H}_{6}$ near the critical point ${ }^{4 j}$. The variation in the ${ }^{14} \mathrm{~N}$ isotropic hyperfine coupling constant, $A_{N}$ in the region 
where the measured esr reaction rate constants over those calculated by Brownian dynamics' (BD) simulations, $\mathrm{k}_{\mathrm{ex}, \mathrm{esr}} / \mathrm{k}_{\mathrm{ex}, \mathrm{BD}}$ attain a maximum, is related to the maximum in the local to bulk solvent density ratio near the free radical, $r_{12}=\rho_{12}$ local $/ \rho_{12}$ bulk for ethane

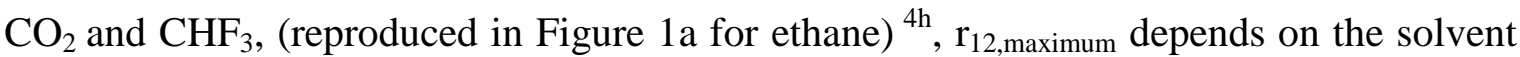
$Z_{c}: r_{12 \text {,maximum }}=-109.93 Z_{c}+33.66$ with a residue $R^{2}=0.9999$. Here the ${ }^{14} \mathrm{~N}$ spin density dependence on the solvent $\left(T_{r}, P_{r}\right)$ and the large $\Delta V^{\ddagger}$ for the activated complex indicate that the solvent is involved in the electron exchange reaction.

- The observed kinetics, by transient spectral measurements after pulse radiolysis ${ }^{4 \mathrm{~g}, \mathrm{l}, \mathrm{o}}$ also indicate that the electron exchange rates are enhanced in fluids near their critical point. The rate constants for electron exchange after pulse radiolysis in $\mathrm{CO}_{2}$ to produce charged free radicals by reaction with p-benzoquinone (BQ), dimethyl aniline (DMA) and $\mathrm{O}_{2}$ in the reactions ${ }^{4 \mathrm{~g}, \mathrm{o}}$ :

$$
\begin{gathered}
(\mathrm{CO} 2)_{\mathrm{n}}^{-}+\mathrm{BQ}=\mathrm{nCO}_{2}+\mathrm{BQ}^{-} \\
\mathrm{C}_{2} \mathrm{O}_{4}^{+}+\mathrm{DMA}=\mathrm{DMA}^{+}+2 \mathrm{CO}_{2} \\
\mathrm{C}_{2} \mathrm{O}_{4}^{+}+\mathrm{O}_{2}=\mathrm{O}_{2}^{+}+2 \mathrm{CO}_{2}
\end{gathered}
$$

are of the same order of magnitude and with a similar dependence on the $\rho_{\mathrm{r}, \mathrm{CO}_{2}}=\mathrm{V}_{\mathrm{c}, \mathrm{CO} 2} / \mathrm{V}$ (Figure 1b) as those reported for DTBN spin exchange in $\mathrm{C}_{2} \mathrm{H}_{6}, \mathrm{CO}_{2}$ and $\mathrm{CHF}_{3}{ }^{4 \mathrm{f}, \mathrm{j}}$. The rate constant for reaction with $\mathrm{O}_{2}$ goes through a maximum just above $\rho_{\mathrm{r}}=0.5$ whereas the rate constants for BQ and DMA appear to approach a maximum below $\rho_{\mathrm{r}}=0.5$. The highest enhancement is observed for the formation of $\mathrm{BQ}^{-}$where our early esr data ${ }^{7 \mathrm{c}}$ shows that the spin density in p-bezosemiquinone extends into the solvent to interact with two solvated ${ }^{23} \mathrm{Na}^{+}$ions in methanol at ambient pressure. 
The object of this work then is to explain the enhanced Heisenberg spin exchange reaction rates by relating the phenomena to the Mott Transition, in order to understand the rate processes involved in the extraction of metal oxides and synthetic chemistry in solvents near their critical point. Spin exchange interactions give rise to the Mott Metal to Insulator Transition where the onset of spin exchange is determined by the simultaneous changes in paramagnetism and metallic behavior ${ }^{3}$, in alkali metal in ammonia solutions, $\mathrm{P}$ doped $\mathrm{Si}$, and in the superconducting cuprates $^{6-8}$. Additional evidence for enhanced electron transfer near the Mott Transition is given by the ease of organic synthesis in metal-ammonia solutions, and the new metallic compounds achieved in fluids near their critical point ${ }^{1}$.

The onset of the Mott Transition at $\mathrm{n}_{\text {Mott }}$ may be achieved near the solvent critical point, it occurs as the free electron concentration approaches a critical value ${ }^{3 b}$ :

$$
\mathrm{n}_{\text {Mott }}=\left(0.25 / \mathrm{a}_{\mathrm{H}}\right)^{3},
$$

where $\mathrm{a}_{\mathrm{H}}=\mathrm{D} \mathrm{m}_{\mathrm{e}} / \mathrm{m}^{*}{ }_{\mathrm{e}}$ bohr is a hydrogenic radius that depends on the dielectric constant $\mathrm{D}$ of the medium and the ratio of the free electron mass to the effective value in the medium, $\mathrm{m}_{\mathrm{e}} / \mathrm{m}_{\mathrm{e}}^{*}$. The effective radius $\mathrm{a}_{\mathrm{H}}$ varies from an $\AA$ for sodium tungstates to over $10^{2} \AA$ for InSb and SnTe alloys ${ }^{3 b}$, but it is important to note that the critical concentration $n_{\text {Mott }}$ is two orders of magnitude lower than that given by $\mathrm{a}_{\mathrm{H}}$. If for a solvent at the critical point $\mathrm{a}_{\mathrm{H}} \sim \mathrm{nm}$ then $\mathrm{n}_{\text {Mott }}<1 \mathrm{M}$ (e.g., solvated electrons and alkali metal in ammonia solutions ${ }^{6}$ ). Thus the spin exchange term is important for electron transfer chemical reactions that occur in metallic, semi-metallic and polar solvents at concentrations of one spin exchanged per $\mathrm{nm}^{3}$ (as shown by the reactions ${ }^{4 f, 0}$ in $\mathrm{CO}_{2}, \mathrm{CHF}_{3}$ and $\mathrm{C}_{2} \mathrm{H}_{6}$ ). Intermolecular spin flips can be propagated by both dipolar and contact electron-nuclear spin-spin interactions, among the solvent molecules, at the densities obtained near the critical point. 
In a many electron system, the spin-spin exchange interaction introduces an energy density term that varies as a function of the transferred electron density, which will be proportional to the solvent density. Thus the additional energy density term, obtained by Thouless for many electron systems ${ }^{5 a}$ and by Clementi for molecules ${ }^{5 b}$, is written as:

$$
e_{\text {Mott }} / V=-3 d(n / V)^{4 / 3},
$$

where $\mathrm{d}$ is a parameter to be determined semi-empirically. The Mott contribution is not expected to be large in polar solvents but it can not be neglected completely, since it is known that the rates of electron exchange are enhanced near the critical point of these solvents ${ }^{1,4}$. The importance of spin-boson interactions has also been described in the Hamiltonian quantum model for electron transfer processes ${ }^{2 c}$.

\section{Phenomenological Equations of State with Spin Exchange}

The three phenomenological relations that are most often used to describe fluids near their critical point are variations of the van der Waals (vdW), the Redlich-Kwong (R-K) and the Anderko-Pitzer (A-P) ${ }^{10}$ EOS. The reduced pressure $\mathrm{P}_{\mathrm{r}}$ is a function of the reduced volume $V_{r}=1 / \rho_{r}$ and the temperature $T_{r}$. Semiempirical corrections to the pressure in the ideal gas relation are due to: the finite volume of the fluid molecules, the polar terms which depend on $\mathrm{V}_{\mathrm{r}}^{-2}, \mathrm{~V}_{\mathrm{r}}^{-3}, \mathrm{~V}_{\mathrm{r}}^{-4}$, and the spin exchange term introduced in this work, which depends on $\mathrm{V}_{\mathrm{r}}^{-4 / 3}$. The EOS near the critical point may be determined by using the thermodynamic relations that identify the critical point:

$$
\mathrm{T}_{\mathrm{r}}=\mathrm{V}_{\mathrm{r}}=\mathrm{P}_{\mathrm{r}}=1, \mathrm{P}_{\mathrm{r}}{ }^{\prime}=\left(\partial \mathrm{P}_{\mathrm{r}} / \partial \mathrm{V}_{\mathrm{r}}\right)_{\mathrm{Tc}}=0 \text {, and } \mathrm{P}_{\mathrm{r}}{ }^{\prime \prime}=\left(\partial^{2} \mathrm{P}_{\mathrm{r}} / \partial \mathrm{V}_{\mathrm{r}}^{2}\right)_{\mathrm{Tc}}=0 \text {, }
$$

the experimental data in Table $\mathrm{I},{ }^{4}$ and the text book relations for the EOS, ${ }^{10}$ with an additional term $-\mathrm{d} \mathrm{V}_{\mathrm{r}}^{-4 / 3}$ in relation (3): 


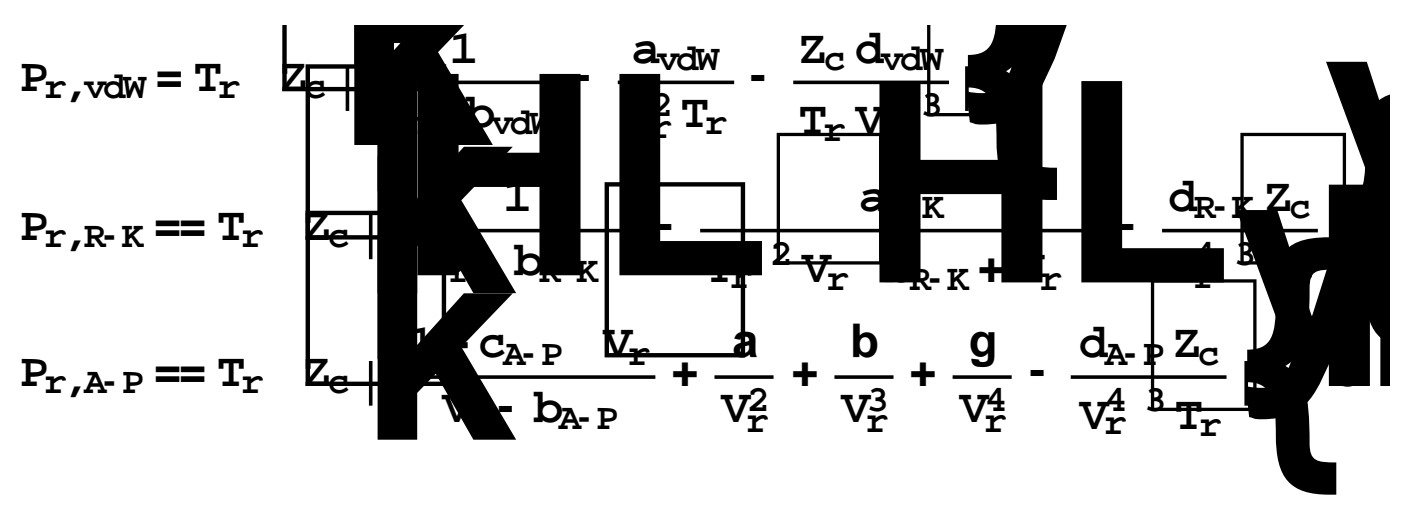

The textbook values ${ }^{10}$ are: $b_{v d W}=1 / 3, Z_{c}(v d W)=3 / 8$, with an internal pressure at $T_{r}=V_{r}=1$ :

$$
-\mathrm{P}_{\mathrm{i}, \mathrm{r}}=-\mathrm{P}_{\mathrm{i}} / \mathrm{P}_{\mathrm{c}}=\left(\partial \mathrm{U}_{\mathrm{i}} / \partial \mathrm{V}\right)_{\mathrm{Tc}} / \mathrm{P}_{\mathrm{c}}=\mathrm{T}_{\mathrm{r}}\left(\partial \mathrm{P}_{\mathrm{r}} / \partial \mathrm{T}_{\mathrm{r}}\right)_{\mathrm{V}}-\mathrm{P}_{\mathrm{r}}=\mathrm{a}_{\mathrm{vdW}} / \mathrm{Z}_{\mathrm{c}}(\mathrm{vdW})=3
$$

when $U_{i}$ is the internal energy; $a_{R-K} / Z_{c}(R-K)=\left(1+2^{1 / 3}+2^{2 / 3}\right), b_{R-K}=-1+2^{1 / 3}$ and $Z_{c}(R-K)$ $=1 / 3$; for spherical molecules at $\mathrm{V}_{\mathrm{r}}=\mathrm{T}_{\mathrm{r}}=1$ : $\mathrm{b}_{\mathrm{A}-\mathrm{P}}=0.25, \mathrm{c}_{\mathrm{A}-\mathrm{P}}=1.33,-(\alpha+\beta+\gamma+\mathrm{c} /(1-$ $\mathrm{b}))=1.047$, and the temperature dependence of $\alpha, \beta, \gamma, \mathrm{b}_{\mathrm{A}-\mathrm{P}}$ and $\mathrm{c}_{\mathrm{A}-\mathrm{P}}$ (given explicitly in ref. 10) obtains: $-\mathrm{P}_{\mathrm{i}, \mathrm{r}}\left(\mathrm{V}_{\mathrm{r}}=\mathrm{T}_{\mathrm{r}}=1\right)=1.54 / \mathrm{Z}_{\mathrm{c}}$. The observed values ${ }^{4 \mathrm{~d}}$, $-\mathrm{P}_{\mathrm{i}, \mathrm{r} \text { experimental }}\left(\mathrm{V}_{\mathrm{r}}=\mathrm{T}_{\mathrm{r}}=1\right)=$ 3.96 for $\mathrm{Hg}$ and 4.22 for Cs, indicate that $\left(\partial \mathrm{d} / \partial \mathrm{T}_{\mathrm{r}}\right)_{\mathrm{V}_{\mathrm{c}}}-\mathrm{d}=1.54 / \mathrm{Z}_{\mathrm{c}}+\mathrm{P}_{\mathrm{i}, \mathrm{r}}$ experimental is non zero.

The parameters for the three EOS (3) near the critical isotherm were obtained using "Mathematica" version 3.0 notebooks. ${ }^{12}$ Typical values are given in Table I together with literature data from various laboratories. ${ }^{4}$ Figure 2 shows the fit of the A-P EOS, determined from a single data point, $\mathrm{Z}_{\mathrm{c}}$ to the experimental data ${ }^{4 \mathrm{a}, \mathrm{i}}$ for $\mathrm{CO}_{2}$ and $\mathrm{C}_{2} \mathrm{H}_{6}$ near their critical point; the average deviation is $2.5 \%$ for $\mathrm{CO}_{2}$, but is not as good for $\mathrm{C}_{2} \mathrm{H}_{6}$. The approach to the critical point for extreme values of $\mathrm{Z}_{c}, \operatorname{Ln}\left|\Delta \mathrm{P}_{\mathrm{i}}\right|$ versus $\mathrm{Ln}|\Delta \rho|$ (when $\Delta \mathrm{P}_{\mathrm{i}}=\left(\mathrm{P}_{i \mathrm{c}^{-}}-\mathrm{P}_{\mathrm{i}}\right) / \mathrm{P}_{\mathrm{i}, \mathrm{c}}$ and $\Delta \rho$ $\left.=\left(\rho_{\mathrm{c}}-\rho\right) / \rho_{\mathrm{c}}\right)$ for $\mathrm{Hg}$, Cs and Rb gives a slope of one for both the experimental ${ }^{4 \mathrm{~d}}$ and the calculated values. Figure 3 shows plots of the isothermal compressibility, $K_{\mathrm{Tc}}=-1 / \mathrm{V}$ $(œ V / œ P)_{T_{c}}$ obtained from relation (3) versus $P_{r}$ for different values of $Z_{c}$ (Hg to $\mathrm{NH}_{3}$ to Se).

Landau and Zel'dovitch ${ }^{13}$ proposed that there were two transitions near the critical point of gaseous metals, one for the fluid and another for the metal condensation. This hypothesis is 
satisfied in the A-P EOS for metals $\left(0.2 \geq Z_{\underline{c}} \geq 0.1\right)$ by imposing 5 boundary conditions in relation (3) to describe the two contiguous phase transitions: $\mathrm{P}_{\mathrm{r}}=\mathrm{V}_{\mathrm{r}}=\mathrm{T}_{\mathrm{r}}=1$, and $\mathrm{P}_{\mathrm{r}}{ }^{\mathrm{i}}=$ $\left(œ^{\mathrm{i}} \mathrm{P}_{\mathrm{r}} / \mathrm{V}_{\mathrm{r}}^{\mathrm{i}}\right)_{\mathrm{Tc}}=0$ when $\mathrm{i}=1$ to 4.

\section{Results:}

The EOS are used to ascertain how the bulk properties of the fluid vary with $Z_{c}$ :

- $\quad$ Three different regions are identified in Figure 4:

- $\quad 0.10 \leq \mathrm{Z}_{\mathrm{c}} \leq 0.2$ identifies a metallic fluid at the critical point.

- $0.20 \leq \mathrm{Z}_{\mathrm{c}} \leq 0.3$ identifies a polar fluid at the critical point.

- $\quad 0.30 \leq \mathrm{Z}_{\mathrm{c}} \leq 0.42$ identifies a non-polar fluid at the critical point.

- $\quad$ The difference between the fluid properties are evident in $\mathrm{K}_{\mathrm{Tc}}$ versus $\mathrm{P}_{\mathrm{r}}$ (Figure 3):

- $\quad \mathrm{K}_{\mathrm{Tc}}(\mathrm{Hg})$ is fairly symmetric about $\mathrm{P}_{\mathrm{r}}=1$, and of the same order of magnitude as the experimental values ${ }^{4 c, d}$ as it goes to infinity when $P_{r}=>T_{r}=1$, but as $Z_{c}$ decreases from $\mathrm{Hg}$ to $\mathrm{CO}_{2}$ to $\mathrm{NH}_{3}$ to $\mathrm{Se}$, the approach to infinity becomes increasingly asymmetric (Figure 2a, insert for $\mathrm{K}_{\mathrm{Tc}}\left(\mathrm{CO}_{2}\right)$ ). Thus, for synthetic work it is useful to note that Se is more compressible than $\mathrm{NH}_{3}$ than $\mathrm{CO}_{2}$ than $\mathrm{Hg}$ and that all are more compressible below $\mathrm{P}_{\mathrm{r}}=1$ than above it.

- The dependence of the individual contributions in the A-P EOS versus $Z_{c}$ give some physical insight in Figure 4:

- The energy contributions at the critical point using the Anderko-Pitzer EOS are:

$$
\begin{aligned}
& \mathrm{E}_{\text {polar }} / \mathrm{RT}_{\mathrm{c}}=\alpha / \mathrm{V}_{\mathrm{r}}, \\
& \mathrm{E}_{\text {hyperpolarizability }} / \mathrm{RT}_{\mathrm{C}}=\left(1 / 2 \beta / \mathrm{V}_{\mathrm{r}}^{2}+1 / 3 \gamma / \mathrm{V}_{\mathrm{r}}^{3}\right), \\
& \mathrm{E}_{\text {spin exchange }} / \mathrm{RT}_{\mathrm{c}}=-3 \mathrm{~d} \mathrm{Z} \mathrm{C}_{\mathrm{c}} / \mathrm{V}_{\mathrm{r}}^{1 / 3}
\end{aligned}
$$


- The ratios of the pressure and energy contributions relative to the second order $\mathrm{V}_{\mathrm{r}}^{-2}$ terms versus $Z_{c}$ show negligible contributions from terms in $V_{r}^{-3}$ plus $V_{r}^{-4}$ while:

$$
\begin{aligned}
& \left(\mathrm{P}_{\text {exchange }} / \mathrm{P}_{\text {polar }}\right)_{\mathrm{Pr}=\operatorname{Tr}=\mathrm{Vr}=1,0.2 \leq \mathrm{Zc} \leq 0.42}=-0.964 \mathrm{Z}_{\mathrm{c}}+0.306 \text { (residue } \mathrm{R}^{2}=0.999 \text { ), } \\
& \left(\mathrm{P}_{\text {exchange }} / \mathrm{P}_{\text {polar }}\right)_{\operatorname{Pr}=\operatorname{Tr}=\mathrm{Vr}=1,0.1 \leq \mathrm{Zc} \leq 0.2}=-9.40 \mathrm{Z}_{\mathrm{c}}+1.672 \text { (residue } \mathrm{R}^{2}=0.97 \text { ). }
\end{aligned}
$$

and

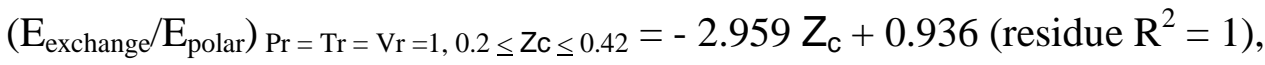

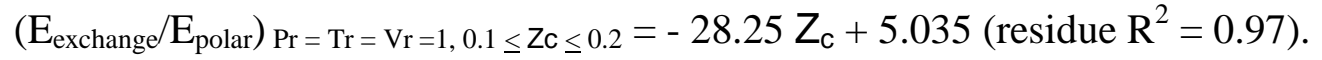

All the energy contributions are an order of magnitude smaller than the fluid Helmholtz free energy, A relative to the standard Gibbs free energy $\mathrm{G}^{0}$ (Figure 5) ${ }^{10}$ :

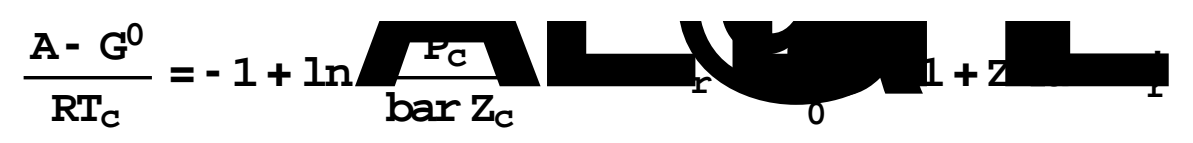

The Mott spin exchange contribution to the pressure gives further physical insight into chemical reactivity. The parameter $\mathrm{d}$ is a measure of the solvent mediated spin exchange near the critical point. It gives the ability of a solvent to mediate electron spin exchange reactions according to $Z_{c}$ in Table I:

- $\quad$ Supercritical Se with metallic conductivity ${ }^{4 d}\left(Z_{c}=0.105\right)$, up to the alkali metals $\left(Z_{c} \leq\right.$ 0.20) appear to be the best solvents for electron spin exchange reactions.

- $\mathrm{D}_{2} \mathrm{O}$ and methanol $\left(Z_{\mathrm{c}}=0.20\right)$ to $\mathrm{NH}_{3}\left(Z_{\mathrm{c}}=0.24\right)$ and $\mathrm{CHF}_{3}\left(Z_{\mathrm{c}}=0.25\right)$ to $\mathrm{CO}_{2}$ and n$\mathrm{C}_{2} \mathrm{H}_{6}\left(\mathrm{Z}_{\mathrm{c}}=0.28\right)$ up to $\mathrm{Xe}\left(\mathrm{Z}_{\mathrm{c}}=0.29\right)$ are the next best solvents.

- $\quad \mathrm{H}_{2},{ }^{4} \mathrm{He}$ and $\mathrm{Ne}\left(\mathrm{Z}_{\mathrm{c}}=0.30\right)$ should make no contribution to spin exchange, and.

- $\quad$ Liquid $\mathrm{Hg}$, In and $\mathrm{Pb}$ with $\mathrm{Z}_{\mathrm{c}}=0.40$ to 0.36 should to be the worst solvents, near their critical point for electron exchange reactions because of clustering. ${ }^{4 d}$ The term $d<0$ indicates repulsive interactions for expanded $\mathrm{Hg}, \mathrm{Pb}$ and In. This agrees with the fact that 
on the high density side of $\left(\mathrm{T}_{\mathrm{c}}, \mathrm{P}_{\mathrm{c}}\right)$ the $\mathrm{Hg}$ conduction is non-metallic and thermally activated, and that the Knight shift plummets to zero, indicating that the electrons are localized in diamagnetic clusters ${ }^{4 c, d}$. The value of $Z_{c}$ predicts that the same should be true for $\mathrm{Pb}$ and In.

The question that remains to be answered is how does the electron osmotic pressure change near the solvent critical point? Thermodynamic data is available $e^{5 c, 6 a, b}$ for the Mott Transition in metal-ammonia solutions at ambient temperatures for $\left[\mathrm{NH}_{3}\right] /[\mathrm{M}] \approx 10^{2}$, or $\rho_{\mathrm{e}, \mathrm{r}}$ $\approx 10^{-2} \rho_{\mathrm{r}}$ (where $\rho_{\mathrm{r}}$ is the solvent reduced density and $\rho_{\mathrm{e}, \mathrm{r}}$ is that for the long lived solvated electron). As the solvent critical point is reached, $\mathrm{a}_{\mathrm{H}}{ }^{-3} / \rho(\mathrm{M}) \approx 10$ obtains $\rho\left(\mathrm{NH}_{3}\right) / \mathrm{a}_{\mathrm{H}}{ }^{-3} \approx 10$ $\left(\rho_{\mathrm{H}, \mathrm{r}}=\mathrm{a}_{\mathrm{H}}^{-3} / \rho_{\mathrm{C}}\left(\mathrm{NH}_{3}\right)\right.$. Using this data, the electron osmotic pressure has been evaluated using the Debye-Hückel theory and the Mott term in relation (3) for the vdW EOS ${ }^{5 c}$ :

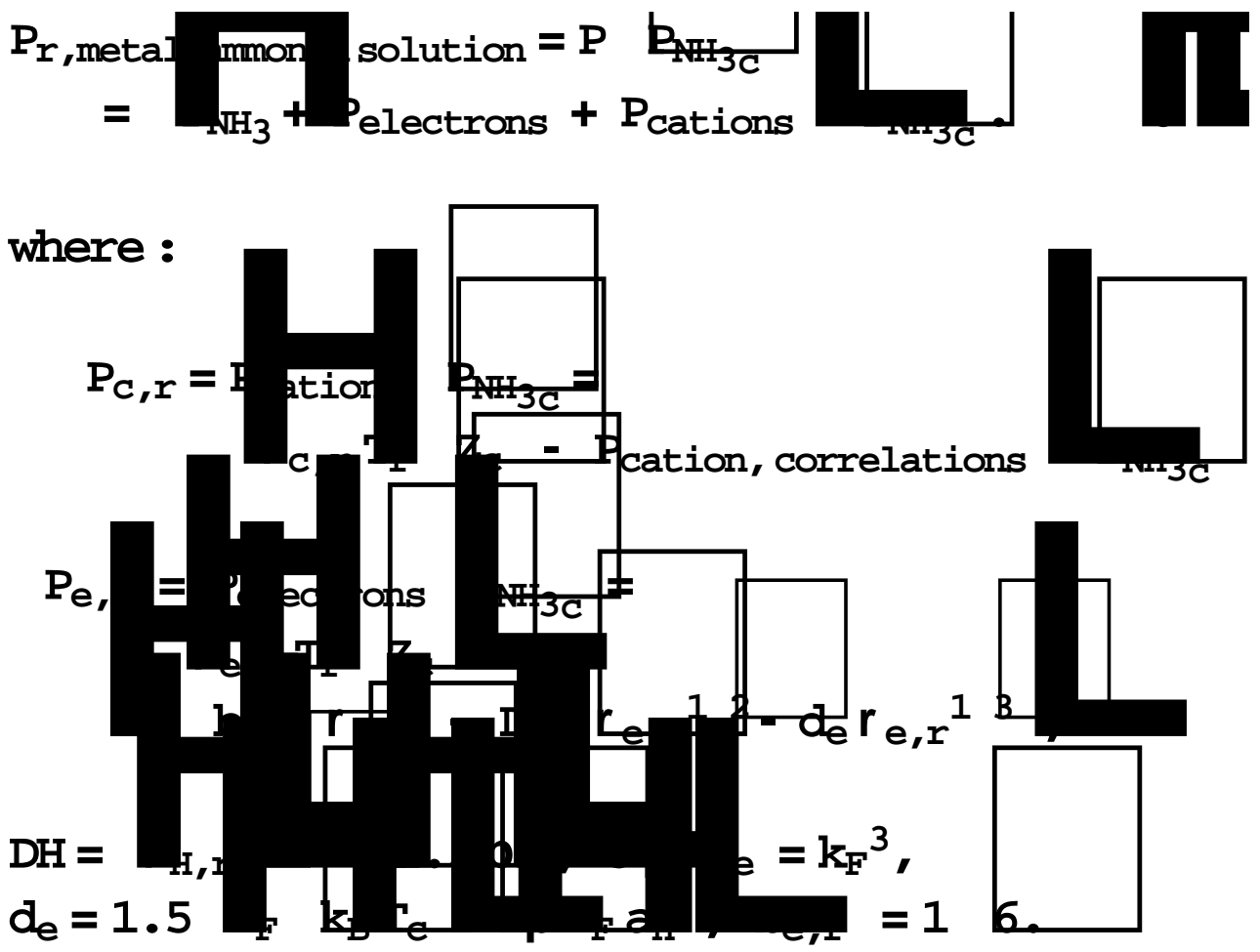

and the effect of the solvated cation reduced density $\rho_{\mathrm{c}, \mathrm{r}}$ is neglected, $\mathrm{E}_{\mathrm{F}}$ is the Fermi energy, 
DH $\rho_{\mathrm{e}, \mathrm{r}}^{1 / 2}$ is the contribution introduced in the Debye-Hückel theory, and $\mathrm{d}_{\mathrm{e}} \rho_{\mathrm{e}, \mathrm{r}}{ }^{4 / 3}$ is the spin exchange term ${ }^{5 c}$. The Debye-Hückel term introduces the effect of local charge structure. Figure 6 shows that the reduced electron osmotic pressure versus the solvent $\rho_{\mathrm{r}}$, at $T_{\mathrm{r}}=1$, increases before the solvent critical point is reached near $\rho_{\mathrm{r}}\left(\mathrm{NH}_{3}\right) \cong 0.5$. This is a typical action-reaction effect; an increase in the solvent pressure induces an increase in the electron osmotic pressure. Since the free electron osmotic pressure goes through a maximum near the same density where esr measurements indicate that there is a maximum in the ratio of the local to bulk solvent density ${ }^{4 j}$, and where the Heisenberg spin exchange rate constants also go through a maximum ${ }^{4 \mathrm{~g}, \mathrm{f}, \mathrm{o}}$ (Figure 1) it follows that the Debye-Hückel approximation can explain measurements which are sensitive to the local solvent structure. The EOS are also correlated to the data:

- The linear correlation between the maximum (which occur for DTBN in $\mathrm{CHF}_{3}, \mathrm{CO}_{2}$ and $\mathrm{C}_{2} \mathrm{H}_{6}$ near $\rho_{\mathrm{r} \text {, solvent }}=0.5$ at $\mathrm{T}_{\mathrm{r}}=1.01^{4 j}$ ) in the local to bulk solvent density ratio around the

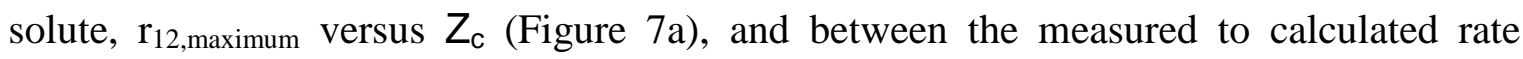
constant ratios, $\mathrm{k}_{\mathrm{ex}, \mathrm{ess}} / \mathrm{k}_{\mathrm{ex}, \mathrm{DB}}(\mathrm{DTBN})_{\max }$ versus $\mathrm{d}$ (Figure $\left.7 \mathrm{~b}\right)$ indicate that the local solvent density enhancement relative to the bulk, the parameter $d$ and the Heisenberg spin exchange interactions are interdependent in $\mathrm{Z}_{\mathrm{c}}$.

- Solvatochromism in fluids near their critical point can be correlated to the relative contributions in the EOS. Interactions with the fluid change the value of the solute optical excitation energy, hv relative to that observed in a normal solvent, $h v_{0}$, e.g., cyclohexane. The polarity parameter, reported for $\mathrm{N}, \mathrm{N}$-dimethyl-4-nitroaniline in $\mathrm{NH}_{3}$ and $\mathrm{CO}_{2}{ }^{4 \mathrm{e}}, \pi^{*}=$ $\mathrm{pi}^{*}=\left(v-v_{0}\right) / \mathrm{s}$ (where $\mathrm{s}$ is a constant) versus the ratio $\mathrm{E}_{\mathrm{r}}(\mathrm{CP})=\mathrm{E}_{\mathrm{polar}} / \mathrm{E}_{\text {exchange }}$ for the solvent (Figure 7c) indicates that though the spin exchange is expected to be small in polarizable 
solvents, $\pi^{*}$ does depend on $Z_{c}$ and increases as the ratio $E_{r}(C P)$ increases. Here $\pi^{*}>0$ indicates that the solute-solvent ground state energy interactions are stronger than in the excited state, whereas $\pi^{*}<0$ indicates the reverse ${ }^{4 \mathrm{n}}$. In solvents with high polarizability, e.g., $\mathrm{NH}_{3}$ and $\mathrm{CO}_{2}$ the dipolar interactions are expected to be highest in the ground state, whereas spin exchange interactions can occur only in the excited state, thus the polar and spin exchange interactions tend to cancel each other so that $\mathrm{p}^{*}$ increases only as $\mathrm{E}_{\mathrm{r}}(\mathrm{CP})$ increases (Figure 7c).

\section{Conclusions/Predictions/Use of Phenomenological EOS:}

The results indicate that an enhanced solvated electron osmotic pressure near the metal to non-metal transition is related to the enhanced local to bulk solvent density ratio, and to the enhanced free radical spin exchange rate constants, observed near the solvent critical point. This suggests that all these properties are related by a universal truth on the nature of spin exchange contained in $Z_{c}$. This should be useful for chemical synthesis as well as metal oxide extraction processes in solvents near their critical point.

\section{Acknowledgements:}

The work is dedicated to K.S. Pitzer whose unique insight has left us the Berkeley legacy that Thermodynamic data must be applied using a simple approach. I am grateful to Jean Pitzer for letting me know his thoughts on a preprint of this work that he read. C. Jonah and G. M. Schneider were very kind to send me reprints and preprints of their work that were used to support the model proposed. J.M. Honig gave me most helpful comments. The work was supported by grant NSF-DMR 9612873 and NSF-INT 9312176. 


\section{References:}

1. (a) P.G. Jessop and W. Leitner, "Chemical Synthesis Using Supercritical Fluids", Wiley,VCH, Germany (1999) ; (b) J.F. Brennecke, D.L. Tomasko and C.A. Eckert, J. Phys. Chem., 94, 7692 (1994); (c) J. Y. Lu, B.R. Cabrera, T. Wang and J. Li, Inorg. Chem., 37, 4480 (1998); (d) J. Li, Z. Chen, K. Lam, S. Mulley and D. Proserpio, Inorg. Chem., 36, 684 (1997); (e) J. Li, Z. Chen, T.J. Emge and D.M. Proserpio, Inorg. Chem., 36, 1437 (1997); (f) S. Kim and K.P. Johnston, Ind. Eng. Chem. Res., 26, 1206 (1987); (g) R.I. Cukier and D.G. Nocera, Ann. Rev. Phys. Chem., H.L. Strauss, ed., 49, 337 (1998); (h) R.L. Smith. T. Yamaguchi, T. Sato, H. Suzuki and K. Sato, Journal of Supercritical Fluids, 13, 29 (1998)

2. (a) H. Taube, Electron Transfer Reactions of Complex Ions in Solution, Academic Press, 1970, NY, London; (b) R. Marcus, J. Chem. Phys., 24, 966; 979 (1956); (c) P.A. Frantsuzov, ibid., 111, 2075 (1999)

3. (a) N. F. Mott, Metal to Insulator Transition, Taylor and Francis, 1974, 1990; (b) N. F. Mott, Conduction in Non-Crystalline Materials, Clarendon Press, Oxford (1987), p. 41; (c) A. S. Alexandrov and N.F. Mott, Polarons and Bipolarons, World Scientific, London(1995)

4. (a) T. Tsuji, S. Honda, T. Hiaki, M. Hongo, Journal of Supercritical Fluids, 13, 15, (1998);

(b) W. C. Reynolds, Thermodynamic Properties in SI, Published by the Department of Mechanical Engineering: Stanford University (1979); (c) F.Hensel, Phase Separations in Expanded Metallic Liquids in Physics and Chemistry of Electrons and Ions in Condensed Matter, ed., J.V. Acrivos, N. F. Mott and A. D. Yoffe, D. Reidel: Dordrecht, 1984, p. 401; (d) F. Hensel and W.W. Warren, Fluid Metals, Princeton University Press, Princeton (1999); (e) G.M. Schneider, Journal of Supercritical Fluids, 13, 5 (1998); (f) T.W. Randolph and C. Carlier, J. Phys. Chem., 96, 5146 (1992) ; (g)N.M. Dimitrijevic, D.M. Bartels, C.D. Jonah and 
K. Tahashi, Chemical Physics Letters, 309, 61 (1999); (h) S. Ganapathy, T.W. Randolph, C. Carlier and J.A. O'Brien, Int. J. of Thermodynamics, 17, 471 (1996); (i) B.A. Younglove and J.F. Ely, J. Phys. Chem. Ref. Data, 16, 577 (1987); (j) S. Ganapathy, C. Carlier, T.W. Randolph and J.A. O'Brien, Ind. Eng. Chem. Res. 35, 19 (1996); (k) J.L. deGrazia, T.W. Randolph and J.A. O'Brien, J.Phys. Chem. A 102, 167 (1998); (l) K. Takahashi, S. Sawamura and C. D. Jonah, Journal of Supercritical Fluids, 13, 155 (1998); (m) G. L. Closs, L.T. Calcaterra, N.J. Green, K. W. Penfield and J.R. Miller, J. Phys. Chem., 90, 3673 (1986); (n) M. Maiwald and G.M. Schneider, Ber. Busenges. Phys. Chem., 102, 960 (1998); (o) N.M. Dimitrijevic, K. Takahashi, D. M. Bartels, C.D. Jonah and A.D. Trifunac, J. Phys. Chem A, in press (1999); (p) S.N. Batchelor, J. Phys. Chem. B 102, 615 (1998)

5. (a) D.J. Thouless, The Quantum Mechanics of Many-Body Systems", Academic Press, New York (1972); (b) E. Clementi, "MOTECC", ESCOM (1991), p.84; (c) J. V.Acrivos, Phil. Mag. 52B, 471 (1985); (d) S. C. Tucker and M. W. Maddox, J. Phys. Chem. B 102, 2437 (1999)

6. (a) C.A. Kraus and W. Lucasse, J. Am. Chem. Soc, 44, 1949 (1922); (b) J.V. Acrivos, J. Phys. Chem., 88, 3740 (1984); (c) P.P. Edwards, ibid., 88, 3772 (1984); (d) G.A. KenneyWallace, G.E. Hall, L.A. Hunt and K. Sarantidis, ibid., 84, 1145 (1980); (e) M. S. Matheson, Solvated Electron, R. F. Gould, ed., 1965, p. 47

7. (a) P.P. Edwards, J. Phys. Chem., 84, 1215 (1980); (b) W. Plachy and D. Kivelson, J. Chem. Phys., 47, 3312 (1967); (c) J.V. Acrivos, ibid, 47, 5389 (1967); (d) B.Bales, "Biological Magnetic Resonance", 8, Berliner, ed., Plenum, p. 77 (1990)

8. (a) D. Issa, A. Ellaboudy, R. Janakiraman and J.L. Dye, J. Phys. Chem., 88, (1984); (b) J.V. Acrivos, Mol. Cryst., 284, 411 (1996) 
9. J.V. Sengers and J.M.H. Levelt Sengers, Ann. Rev. Phys. Chem. 37, 189 (1986)

10. K. S.Pitzer, Thermodynamics, Mc Graw Hill Inc, New York (1994)

11 (a) A. Anderko, and K.S. Pitzer, Am. Inst. Chem. Eng. J., 1991, 37, 1379; (b) K.S. Pitzer, J. Am. Chem. Soc., 80, 5046 (1958); J. Phys. Chem., 77, 268 (1973); ibid., 88, 2689 (1984).

12. S. Wolfram, The Mathematica Book, Cambridge University Press, 1993

13. (a) L. D. Landau and G.Zel'dovitch, Acta Phys. Chim. USSR, 18, 194 (1943); (b) E. M. Lifshitz and L.D. Landau, Statistical Physics, Vol. 1, Pergamom, New York, 1993; E. M. Lifshitz, L. P.Pitaevskii, Statistical Physics, Vol. 2, Pergamom, New York, 1980. 
Table I: Critical point data taken from ref. 4a (T), 10 (P), 4c, d (H and H\&W), 4b (R) and 9 (L\&S) together with the EOS parameters obtained from relations (3). Data from different laboratories indicate the accuracy expected. The ratio of energy contributions at the critical point $\mathrm{E}_{\mathrm{r}}(\mathrm{CP})=\mathrm{E}_{\text {polar }} / \mathrm{E}_{\text {spin exchange }}$ gives the relative importance of the two terms. Unless indicated, the A-P EOS parameters $\alpha=-2.74, \mathrm{c}=1.33$ and $\mathrm{b}=0.25$ in ref. 10 are left unchanged to solve (3) for d, $\beta, \gamma$ to obtain the pressure and energies in Figure 4 versus $Z_{c}$.

\begin{tabular}{|c|c|c|c|c|c|c|c|c|c|c|c|c|c|c|}
\hline & \multicolumn{5}{|c|}{ Experimental Data } & \multicolumn{3}{|c|}{ A-P EOS } & \multicolumn{3}{|c|}{ vdW EOS } & \multicolumn{3}{|c|}{ R-K EOS } \\
\hline FLUID & Tc (K) & Pc (bar) & $\mathrm{V}_{\mathrm{c}}(\mathbf{c c})$ & REF. & $\overline{Z c}$ & $\operatorname{Er}(\mathrm{CP})$ & & d & $\mathbf{a}$ & $\mathbf{b}$ & $\operatorname{Er}(\mathrm{CP})$ & $\mathbf{a}$ & b & $\mathrm{Er}(\mathrm{CP}$ \\
\hline $\mathrm{Hg}$ & 1750 & 1671 & 34.89 & $\mathrm{H}$ & 0.401 & -3.8 & -2.74 & -0.6 & 1.23 & 0.34 & -3.8 & 1.74 & 0.28 & -0.8 \\
\hline In & 6973 & 4000 & 54.67 & $\mathrm{H} \& \mathrm{~W}$ & 0.377 & & & & & & & & & \\
\hline $\mathbf{P b}$ & 5373 & 2500 & 64.75 & $H \& W$ & 0.362 & -7.6 & -2.74 & -0.3 & & & & & & \\
\hline $\mathrm{Ne}$ & 44.4 & 27.6 & 41.70 & $P$ & 0.312 & 60 & -2.74 & 0.04 & & & & & & \\
\hline $\mathrm{H}_{2}$ & 33.2 & 13 & 65.00 & $P$ & 0.306 & & & & & & & & & \\
\hline $4 \mathrm{He}$ & 5.2 & 2.275 & 57.48 & $\mathrm{R}$ & 0.302 & 33 & -2.74 & 0.09 & 0.82 & 0.30 & 0.9 & 1.07 & 0.25 & 2.1 \\
\hline $\mathrm{H} 2$ (para) & 32.938 & 12.838 & 64.29 & $\mathrm{R}$ & 0.301 & & & & & & & & & \\
\hline $\mathrm{Ar}$ & 150.86 & 48.979 & 74.57 & $\mathrm{P}$ & 0.291 & 12.7 & -2.74 & 0.24 & & & & & & \\
\hline $\mathrm{Ar}$ & 150.7 & 48.649 & 77.88 & $\mathrm{R}$ & 0.302 & & & & & & & & & \\
\hline $\mathrm{Kr}$ & 209.39 & 54.96 & 92.00 & $P$ & 0.290 & & & & & & & & & \\
\hline Xe & 289.74 & 58.4 & 119.50 & $P$ & 0.290 & & & & & & & & & \\
\hline methane & 190.555 & 45.988 & 99.93 & $\mathrm{R}$ & 0.290 & & & & & & & & & \\
\hline N2 & 126.2 & 34 & 89.20 & $P$ & 0.289 & & & & & & & & & \\
\hline N2 & 126.21 & 33.98 & 89.30 & L\&S & 0.289 & 11.8 & -2.74 & 0.27 & & & & & & \\
\hline $\mathrm{O}_{2}$ & 154.6 & 50.5 & 73.40 & $\mathrm{R}$ & 0.288 & & & & & & & & & \\
\hline t-MeAmine & 433.2 & 40.7 & 254.00 & $\mathrm{P}$ & 0.287 & & & & & & & & & \\
\hline $\mathrm{H}_{2} \mathrm{~S}$ & 373.2 & 89.4 & 98.50 & $P$ & 0.284 & & & & & & & & & \\
\hline $\mathrm{n}-\mathrm{C}_{2} \mathrm{H}_{6}$ & 305.34 & 48.714 & 145.50 & $P$ & 0.279 & 11.30 & -2.75 & 0.29 & & & & & & \\
\hline $\mathrm{C}_{3} \mathrm{H}_{6}$ & 364.75 & 46.01 & 180.59 & L\&S & 0.274 & & & & & & & & & \\
\hline $\mathrm{CO}_{2}$ & 304.21 & 73.834 & 94.83 & $\mathrm{~T}$ & 0.277 & & & & & & & & & \\
\hline $\mathrm{CO}_{2}$ & 304.21 & 73.825 & 94.43 & $\mathrm{R}$ & 0.276 & 13.9 & -2.76 & 0.24 & & & & & & \\
\hline pyridine & 620 & 56.3 & 254.00 & $\mathrm{P}$ & 0.277 & & & & & & & & & \\
\hline $\mathrm{SO}_{2}$ & 430.8 & 78.8 & 122.00 & $P$ & 0.268 & & & & & & & & & \\
\hline $\mathrm{C}_{2} \mathrm{H}_{4}$ & 282.346 & 50.403 & 121.48 & L\&S & 0.261 & & & & & & & & & \\
\hline n-C8H18 & 568.76 & 24.87 & 492.40 & $P$ & 0.259 & & & & & & & & & \\
\hline $\mathrm{CHF}_{3}$ & 299.1 & 48.2 & 133.30 & $P$ & 0.258 & 7.4 & -2.76 & 0.48 & 0.54 & 0.26 & 0.9 & 0.66 & 0.22 & 0.4 \\
\hline $\mathrm{NH} 3$ & 406.8 & 116.27 & 71.68 & $R, P$ & 0.246 & 6.50 & -2.77 & 0.58 & & & & & & \\
\hline ethanol & 513.85 & 61.37 & 166.91 & B & 0.240 & & & & & & & & & \\
\hline $\mathrm{H}_{2} \mathrm{O}$ & 647.286 & 220.89 & 56.83 & $\mathrm{R}$ & 0.233 & & & & & & & & & \\
\hline $\mathrm{H}_{2} \mathrm{O}$ & 647.07 & 220.46 & 55.78 & L\&S & 0.229 & 5.00 & -2.77 & 0.80 & & & & & & \\
\hline acetone & 508.1 & 47 & 209.00 & $P$ & 0.233 & & & & & & & & & \\
\hline methanol & 566.55 & 80.92 & 117.80 & B & 0.202 & & & & & & & & & \\
\hline D2O & 643.89 & 216.73 & 50.61 & L\&S & 0.205 & & & & & & & & & \\
\hline Cs & 2047.79 & 117.3 & 316.45 & $\mathrm{R}$ & 0.218 & 3.4 & -2.74 & 1.21 & 0.43 & 0.24 & 0.6 & 0.51 & 0.21 & 0.3 \\
\hline Cs & 1924 & 92.5 & 349.74 & $H \& W$ & 0.202 & & & & & & & & & \\
\hline $\mathbf{R b}$ & 2017 & 124.5 & 294.72 & $H \& W$ & 0.219 & & & & & & & & & \\
\hline $\mathbf{R b}$ & 2105 & 133.9 & 230.84 & $\mathrm{R}$ & 0.177 & & & & & & & & & \\
\hline Li & 3800 & 970 & 69.40 & $\mathrm{R}$ & 0.213 & & & & & & & & & \\
\hline Li & 3273 & 690 & 63.10 & $H \& W$ & 0.160 & & & & & & & & & \\
\hline $\mathrm{Na}$ & 2573 & 341 & 111.60 & $\mathrm{R}$ & 0.178 & & & & & & & & & \\
\hline K & 2178 & 148 & 217.22 & $H \& W$ & 0.178 & & & & & & & & & \\
\hline $\mathrm{K}$ & 2173 & 167 & 193.56 & $\mathrm{R}$ & 0.179 & 3.00 & -2.88 & 1.79 & & & & & & \\
\hline Mo & 14300 & 5700 & 33.08 & $\mathrm{H}$ & 0.159 & 1.6 & -2.50 & 3.3 & 0.09 & 0.16 & 0.1 & 0.10 & 0.16 & 0.03 \\
\hline $\mathrm{Se}$ & 1888 & 385 & 42.68 & $\mathrm{H} \& \mathrm{~W}$ & 0.105 & 0.50 & -1.60 & 9.3 & & & & 0.20 & 0.17 & 0.1 \\
\hline
\end{tabular}




\section{List of Figures:}

Figure 1: Evidence for enhanced electron exchange rate constants of solutes in solvents $\left(\mathrm{CO}_{2}\right.$ and in ethane) below their critical point: (a) Correlation between the ratios of experimental to calculated rate constants ( $\left.\mathrm{k}_{\mathrm{ex}, \mathrm{es}} / \mathrm{k}_{\mathrm{ex}, \mathrm{BD}}\right)$ to those of local to bulk solvent (1) density around the solute(2), $\rho^{\text {local }}{ }_{12} / \rho^{\text {bulk }}{ }_{12}$ from esr data (ref. $4 \mathrm{j}$ ). (b) Normalized exchange rate constant for the formation of $\mathrm{BQ}^{-}$, $\mathrm{DMA}^{+}$and $\mathrm{O}_{2}{ }^{+}$after pulse radiolysis in $\mathrm{CO}_{2}, \mathrm{r}_{\mathrm{k}}=\mathrm{k}_{\mathrm{ex}}\left(\rho_{\mathrm{r}}\right) / \mathrm{k}_{\mathrm{ex}}(1.5)$ plotted versus $\rho_{\mathrm{r}}$ using the data in ref. $4 \mathrm{o}$.

Figure 2: $\mathrm{Z}$ versus $\mathrm{P}_{\mathrm{r}}$ near $\mathrm{T}_{\mathrm{c}}$ : (a) Experimental data for $\mathrm{CO}_{2}$ (ref. 4a) are compared to the calculated values at $\mathrm{T}_{\mathrm{r}}=1,1.02,1.05$, insert shows the isothermal compressibility, $\mathrm{K}_{\mathrm{Tc}}$ for the A-P EOS including the spin-spin exchange; the average deviation is $2.5 \%$. (b) Experimental data for $\mathrm{C}_{2} \mathrm{H}_{6}$ and EOS fit near $\mathrm{T}_{\mathrm{r}}=1$; the fit is worse than for $\mathrm{CO}_{2}$.

Figure 3: $\mathrm{K}_{\mathrm{Tc}}$ evaluated from the critical isotherms obtained using relations (3) and the experimental value of $Z_{c}$ (Table I). Five boundary conditions are used in (3) for $Z_{c} \leq 0.18$ ). The parameters used are:

$\mathrm{NH}_{3}: b=0.26, c=123, a=-2.77, g=-0.399, b=0.47, d=0.355$

Se : $g=-0.25, b=-0.0035, a=-1.57, d=10.277, b=0.22, c=1.33$

$K: g=-0.577, b=0.729, a=-2.81, d=2.14, b=0.27, c=1.33$

(a) $\mathrm{K}_{\mathrm{Tc}}\left(\mathrm{Z}_{\mathrm{c}}=0.4\right)$. (b) $\mathrm{K}_{\mathrm{Tc}}\left(\mathrm{Z}_{\mathrm{c}}=0.25\right.$ and 0.11). Though the finite volume parameters $\mathrm{b}(\mathrm{Hg})=$ $0.25, \mathrm{~b}\left(\mathrm{NH}_{3}\right)=0.26$ and $\mathrm{b}(\mathrm{Se})=0.22$ are close, the isothermal compressibility $\mathrm{K}_{\mathrm{Tc}}$ versus $\mathrm{P}_{\mathrm{r}}$, 
at $\mathrm{T}_{\mathrm{r}}=1$ shows that $\mathrm{Hg}$ is the least compressible and $\mathrm{NH}_{3}$ is less compressible than Se for a given $\mathrm{P}_{\mathrm{r}}$ near the critical point. This may be important for synthesis work near the critical point of fluids.

Figure 4: Contributions to the pressure and to the energy relative to the second order term in the density versus $Z_{c}$ at the critical point for the A-P EOS from Mo to Hg. $b_{A-P}, c_{A-P}$, and a were taken from literature values for a given accentric factor $\mathrm{w}^{10}{ }^{10}$ The linear fit does not depend on the accentric factor $\mathrm{w}^{10}$ in relations (4).

Figure 5: $\left(A-G^{0}\right) / \mathrm{RT}_{\mathrm{c}}$ for different solvents: $\mathrm{Hg} \geq \mathrm{Mo}>\mathrm{H}_{2} \mathrm{O}>\mathrm{NH}_{3}>\mathrm{CO}_{2}>\mathrm{He}>\mathrm{Cs}>\mathrm{C}_{8} \mathrm{H}_{18}$.

Figure 6: Osmotic pressure for the solvated electron in alkali metal solutions in $\mathrm{NH}_{3}$ at $\mathrm{T}_{\mathrm{r}}\left(\mathrm{NH}_{3}\right)=1$ and its first derivative relative to $\mathrm{V}_{\mathrm{r}}$, versus $\rho_{\mathrm{r}}\left(\mathrm{NH}_{3}\right)$.

Figure 7: Correlation of the experimental data to the parameters in Table I: . (a) $r_{12, \max }=$ $\left(\rho_{12}^{\text {local }} / \rho_{12}{ }^{\text {bulk }}\right)_{\max }$ for different solvents (data of ref, $\left.4 \mathrm{~h}\right)$ versus $Z_{c}$. (b) $\left(k_{\mathrm{ex}, \mathrm{es} r} / \mathrm{k}_{\mathrm{ex}, \mathrm{BD}}\right)_{\max }$ for DTBN in different solvents (data of ref, 4h) versus d. (c) Polarity parameter $\pi^{*}$ for N,Ndimethyl-4-nitroaniline in $\mathrm{NH}_{3}$ and $\mathrm{CO}_{2}$ measured by the shifts in the absorption maxima in the fluid under test at $v$ relative to $v_{0}$ in a normal liquid solvent (cyclohexane): $\pi^{*}=\mathrm{pi}^{*}=(v$ $\left.v_{0}\right) / \mathrm{s}$ (data of ref. $4 \mathrm{e}$ ) versus the ratio of polar energy to spin exchange energy at the critical point $\mathrm{E}_{\mathrm{r}}(\mathrm{CP})=\mathrm{E}_{\text {polar }} / \mathrm{E}_{\text {spin exchange }}$ 
Figure 1b

$r_{k}=k_{e x} / k_{e x}\left(\rho_{r}=1.5\right)$ in $C O_{2}$ vs $\rho r$

(Data: Dimitrijevic, Takahashi, Bartels, Jonah and Trifunac, 1999)

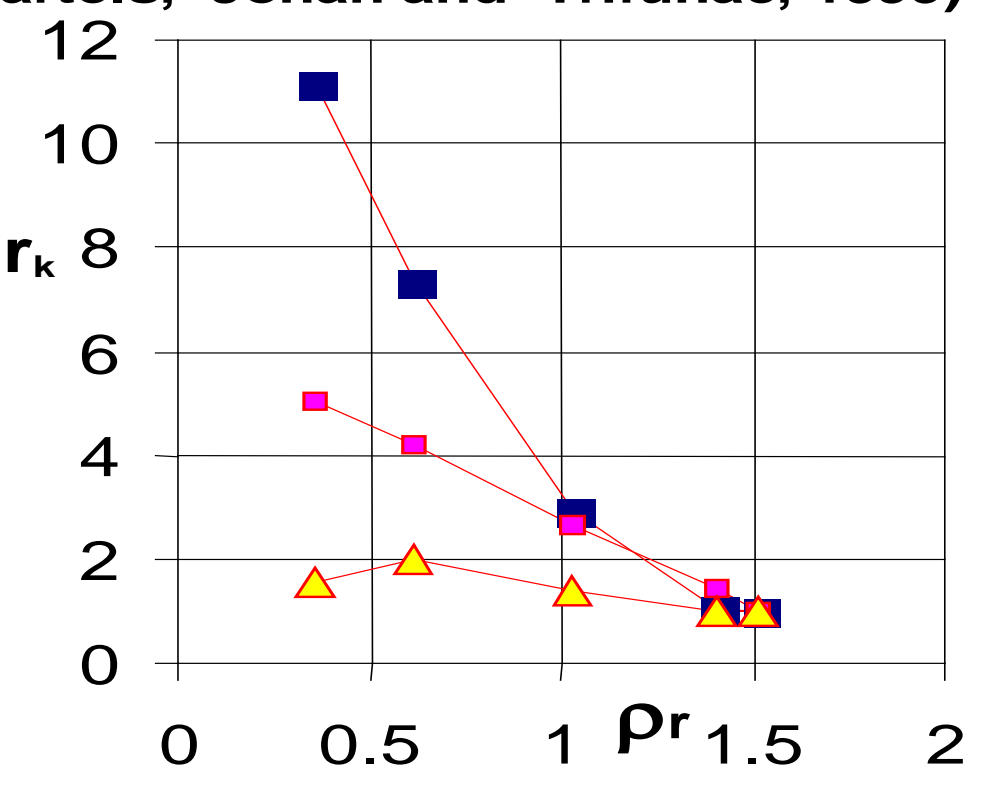

\begin{tabular}{|c|c|}
\hline 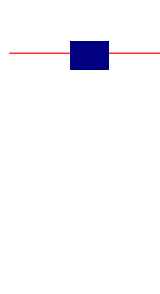 & $\begin{array}{l}\mathrm{BQ}, \\
\mathrm{k}(1)= \\
0.1 \\
\mathrm{l} / \mathrm{mol} / \mathrm{ps}\end{array}$ \\
\hline$=$ & $\begin{array}{l}\text { DMA, } \\
\mathrm{k}(1)= \\
0.22 \\
\mathrm{l} / \mathrm{mol} / \mathrm{ps}\end{array}$ \\
\hline$\triangle$ & $\begin{array}{l}\mathrm{O}_{2}, \\
\mathrm{k}(1)= \\
0.06 \\
\mathrm{l} / \mathrm{mol} / \mathrm{ps}\end{array}$ \\
\hline
\end{tabular}

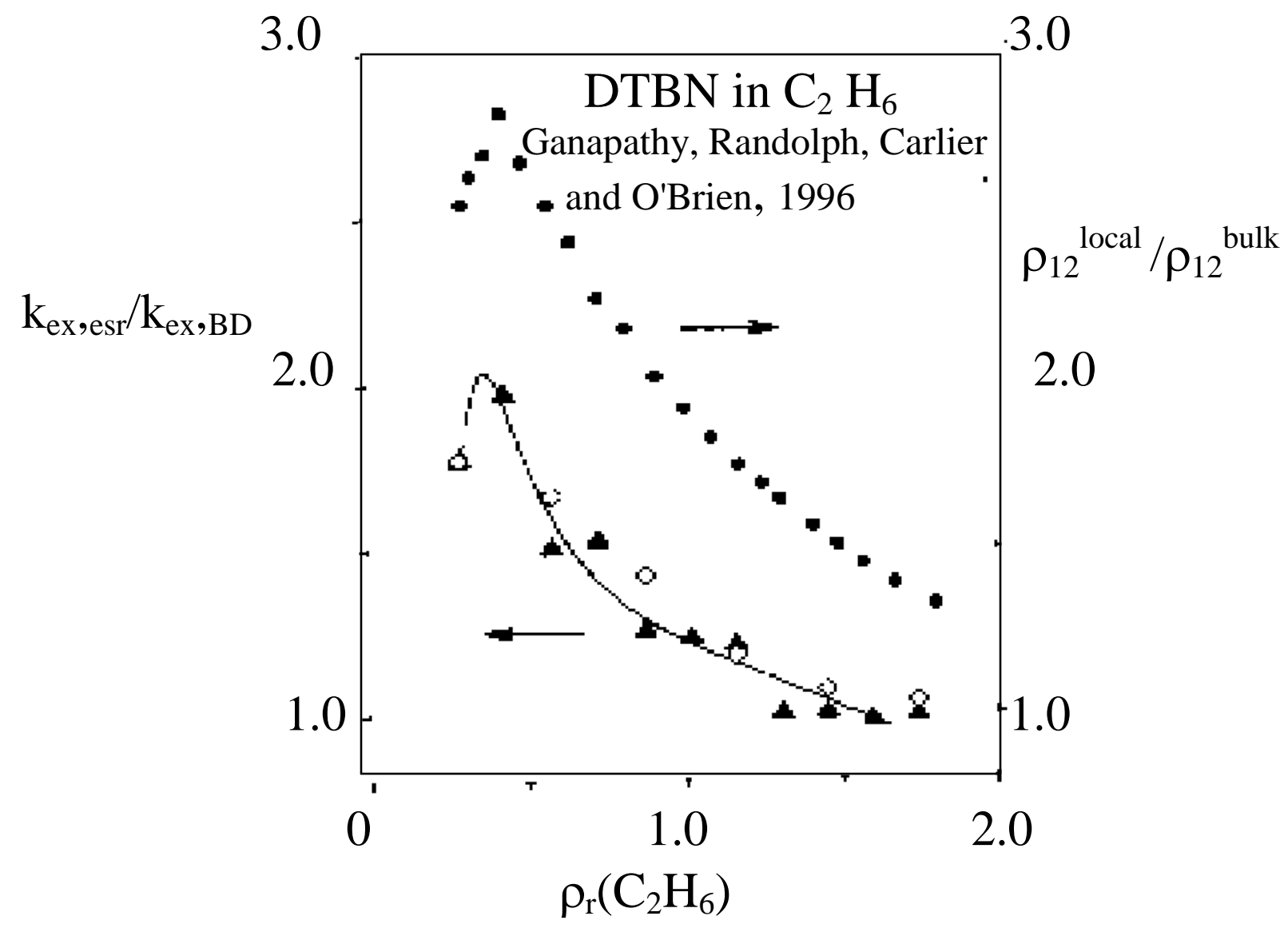

Figure 1a 


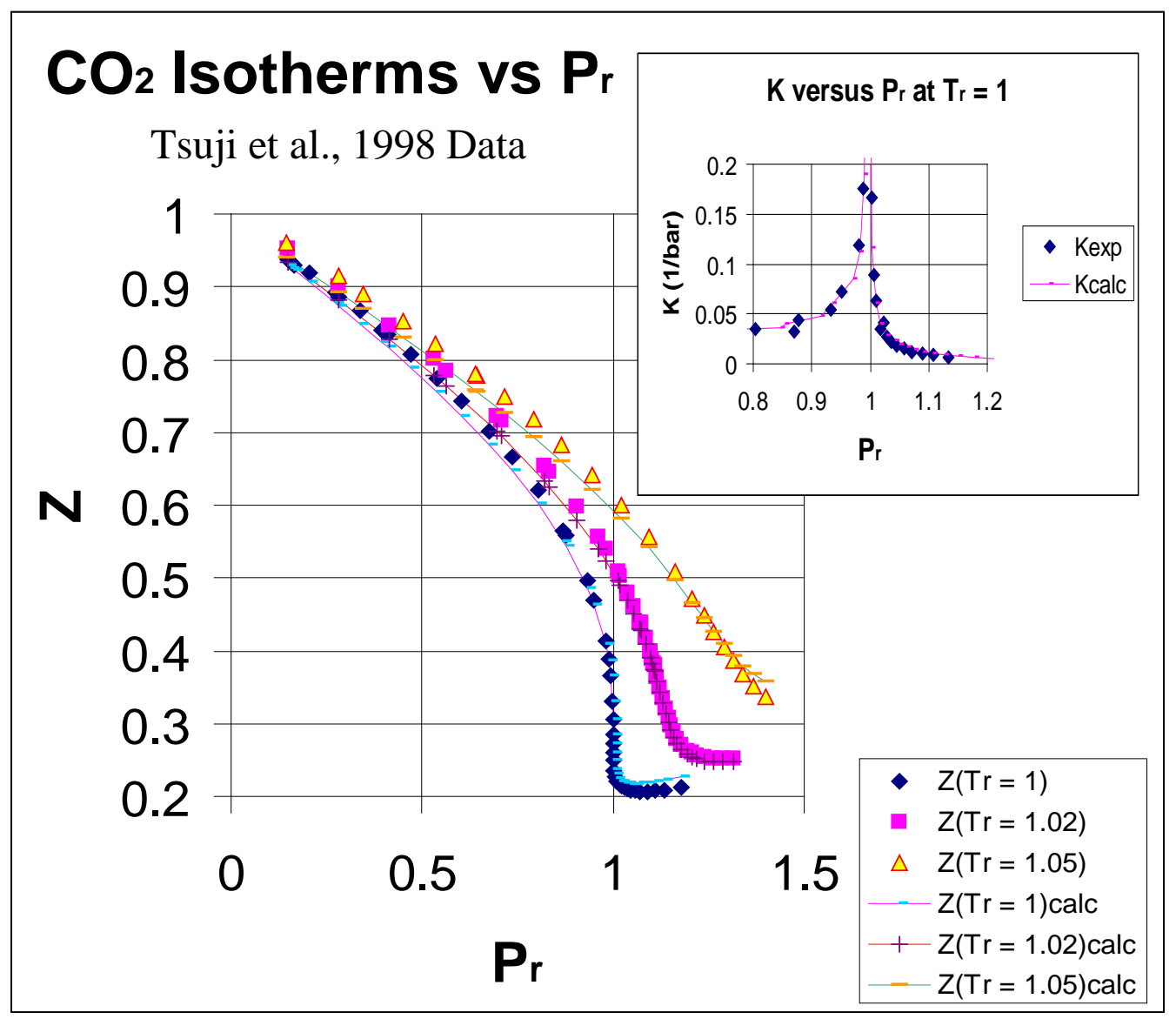

Figure 2a

Figure 2b

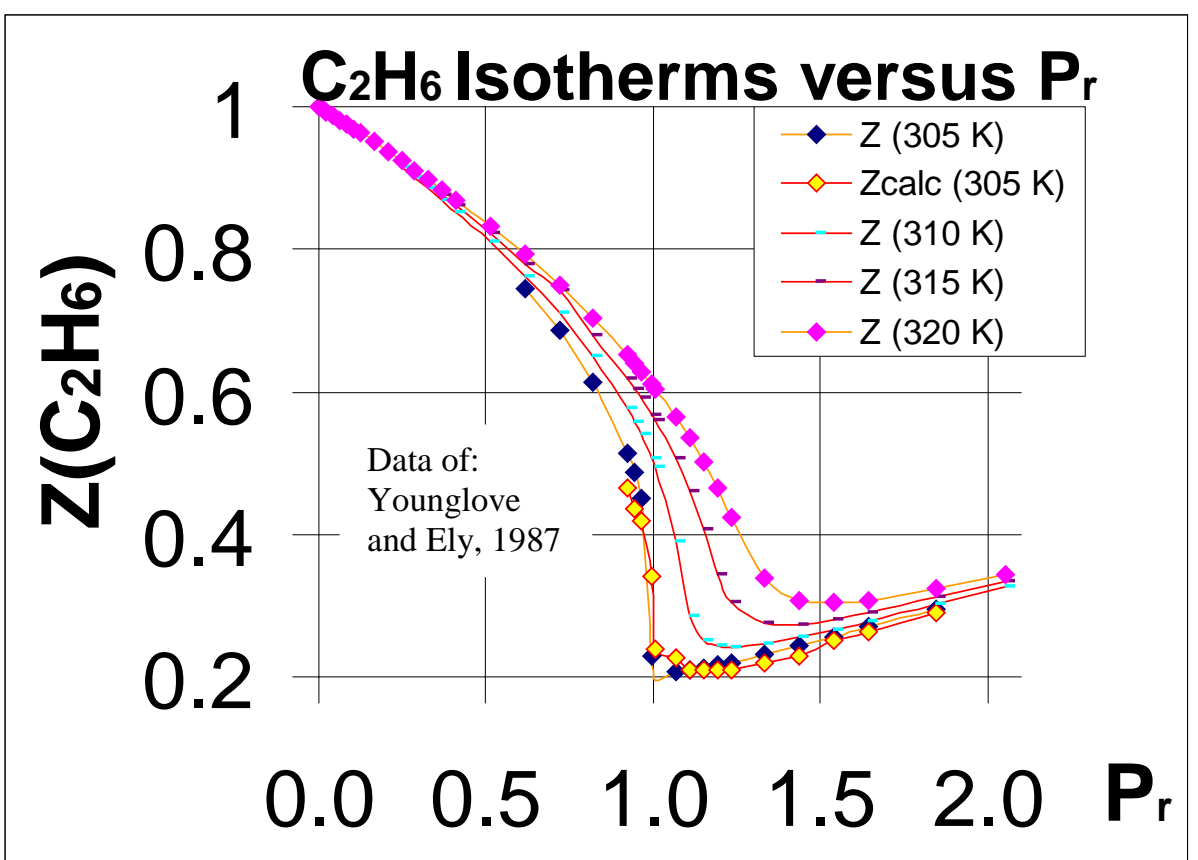


Figure 3a

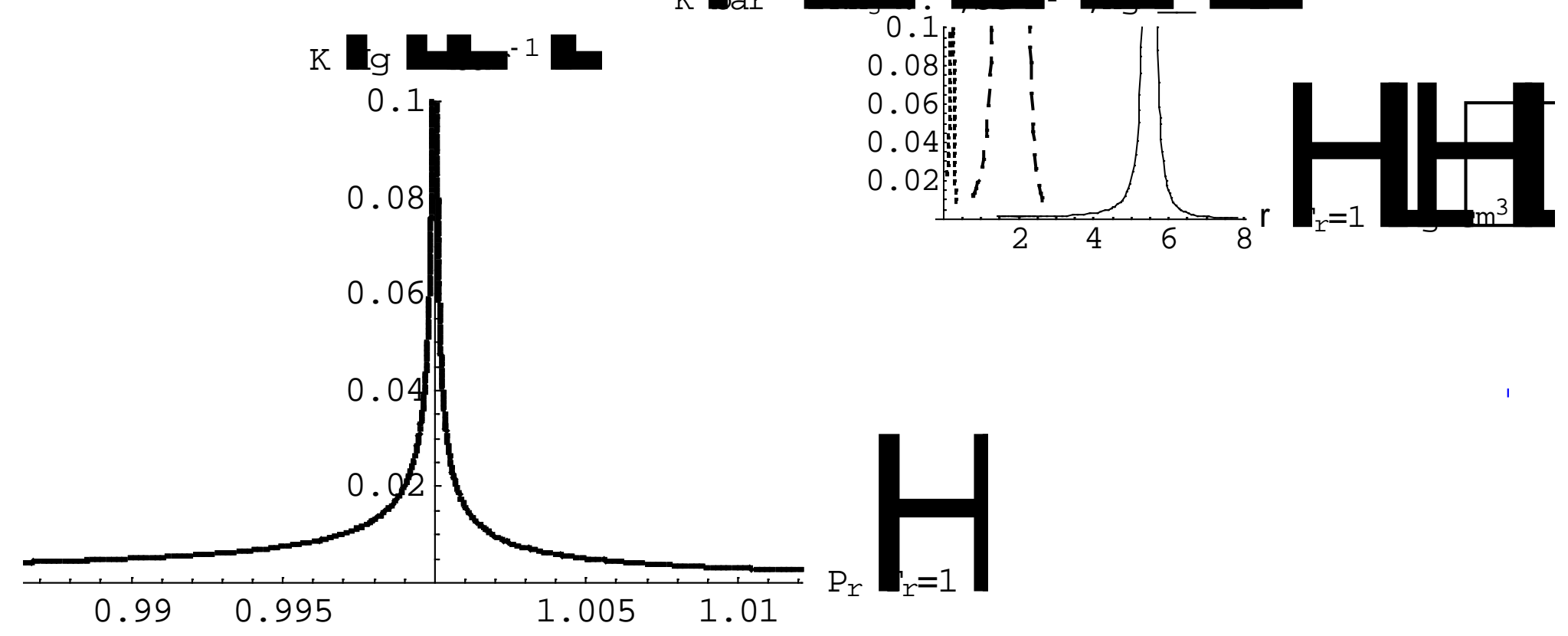

Figure 3b

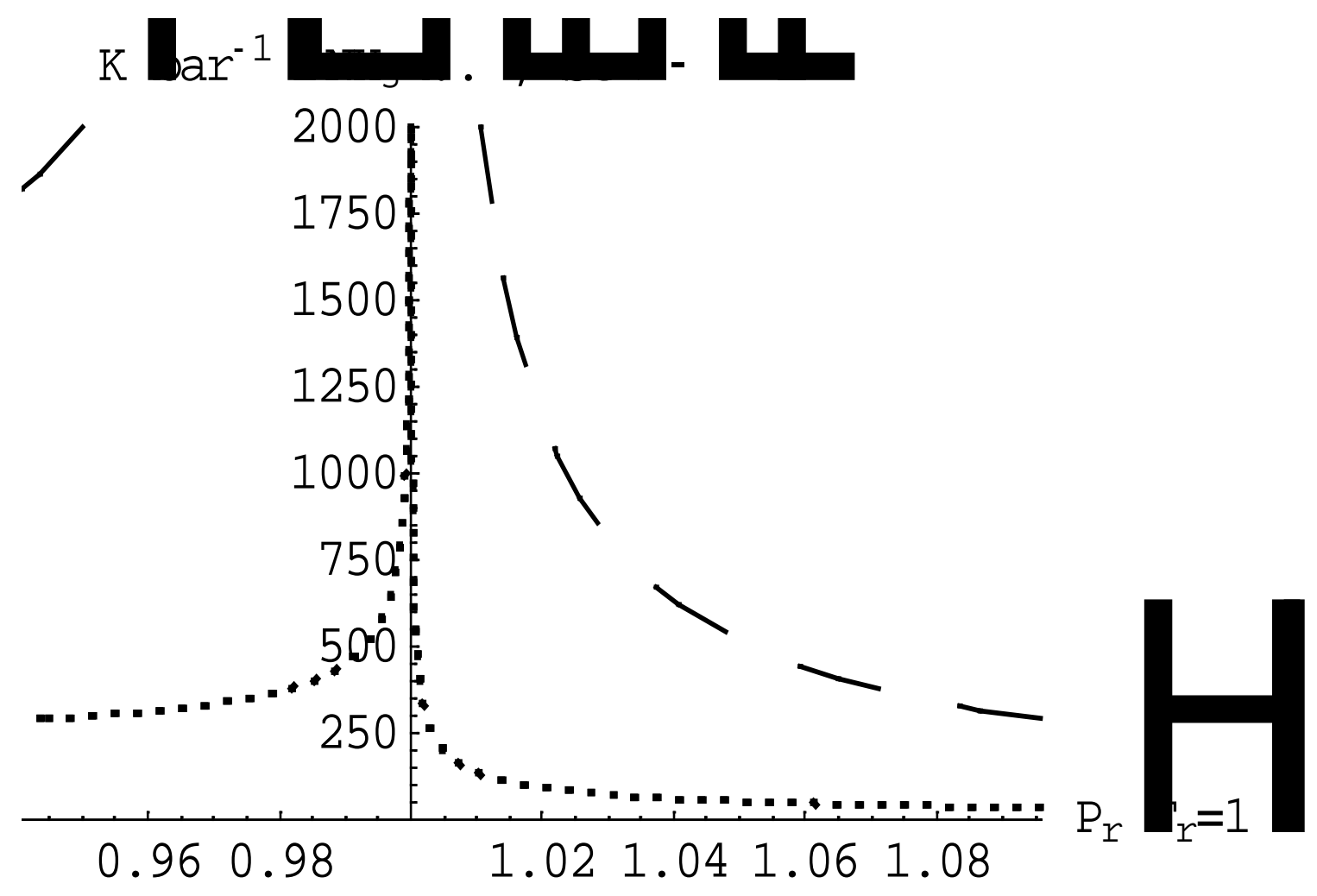



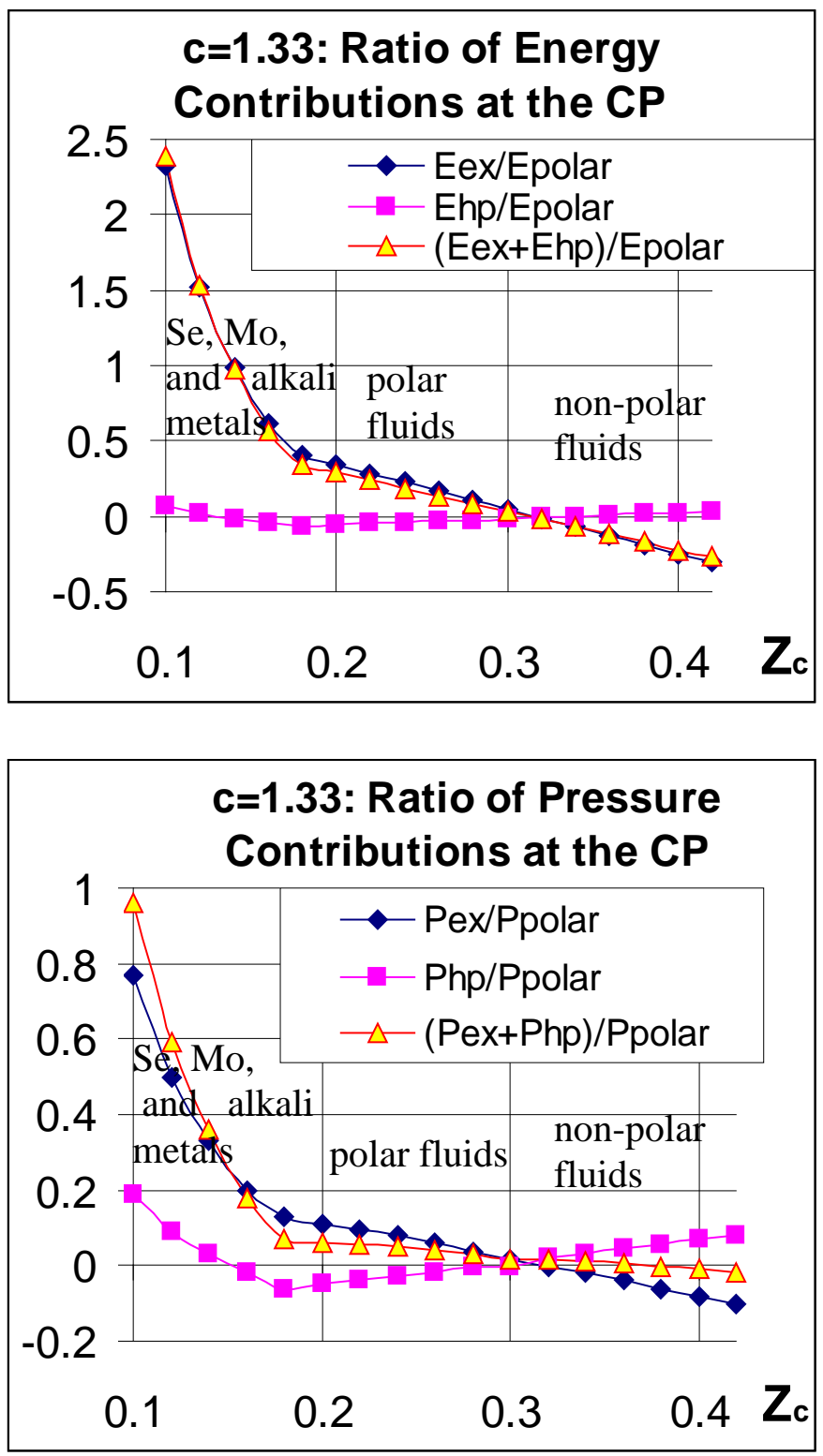

Figure 4 


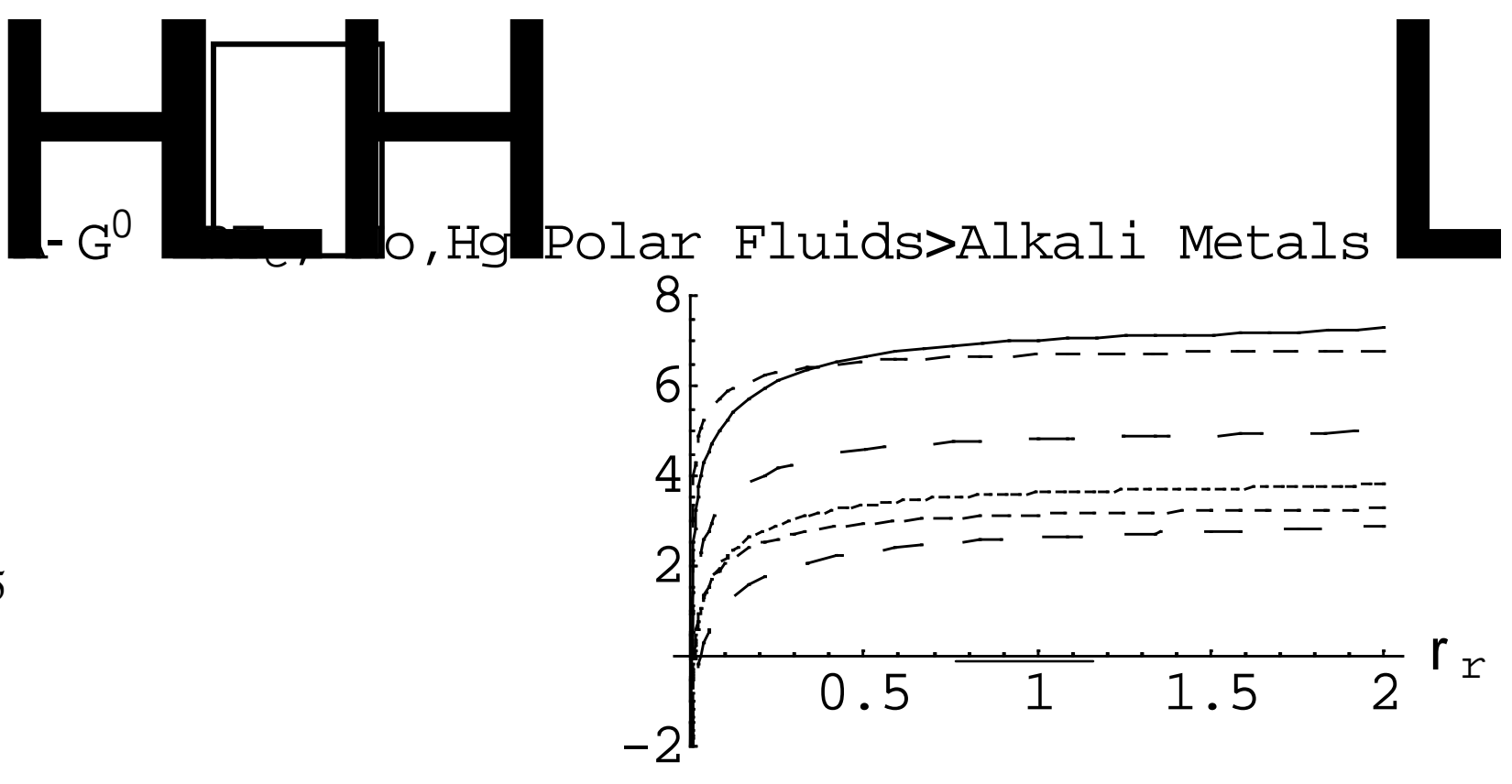

Figure 6

Figure 5

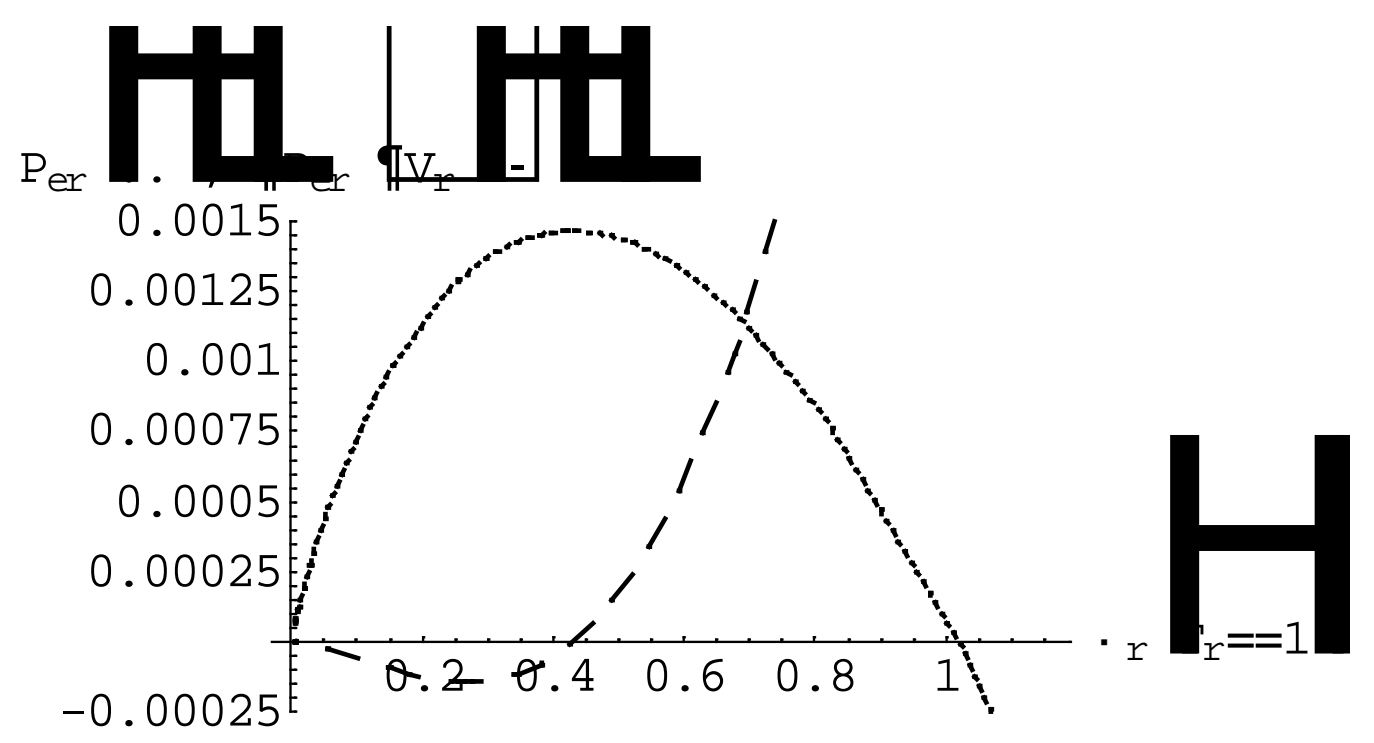


Polarity Parameter $\pi^{*}$, Schneider, 1998

Figure 7c

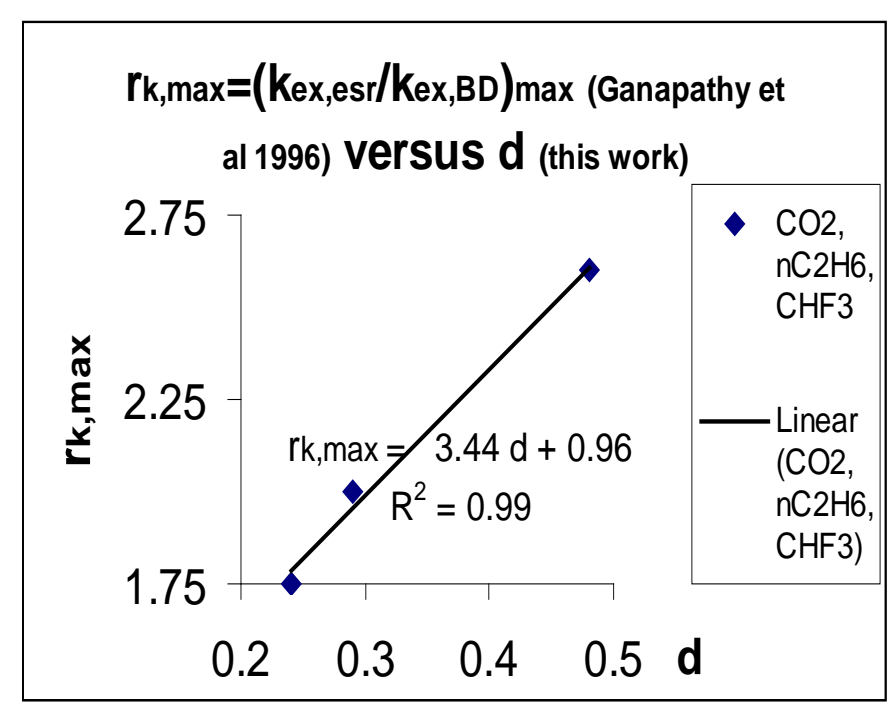

Figure 7b

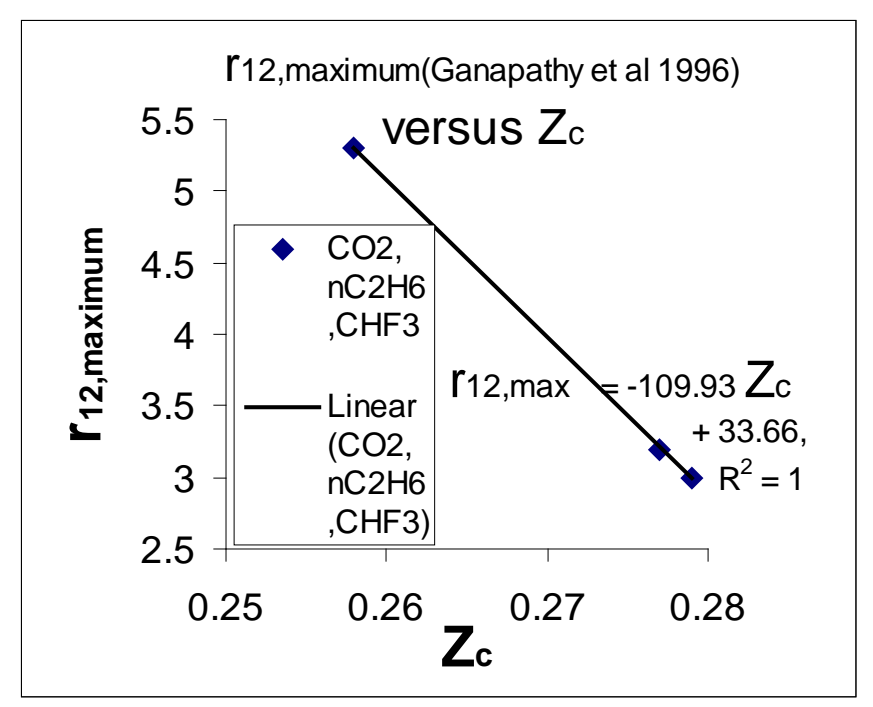

Figure 7a 
